\title{
Hepatitis B Virus S Mutants in Liver Transplant Recipients Who Were Reinfected Despite Hepatitis B Immune Globulin Prophylaxis
}

\author{
Marc G. Ghany, ${ }^{1}$ Brick Ayola, ${ }^{1}$ Federico G. Villamil, ${ }^{2}$ Robert G. Gish, ${ }^{3}$ Sergio Rojter, ${ }^{2}$ John M. Vierling, ${ }^{2}$ \\ AND ANNA S. F. LOK ${ }^{1}$
}

SEE EDITORIAL ON PAGE 294

Long-term hepatitis B immune globulin (HBIG) has been shown to reduce hepatitis B virus (HBV) reinfection in patients transplanted for hepatitis $B$. The aim of this study was to determine the prevalence of HBV S gene mutations in liver transplant recipients who developed recurrent hepatitis B despite HBIG prophylaxis, and to determine if these mutations can revert after withdrawal of HBIG. The entire $S$ gene sequences in pre- and posttransplant sera from 20 patients who developed recurrent hepatitis B despite HBIG prophylaxis were compared. Ten (50\%) patients had 18 amino acid substitutions involving the 'a' determinant in the posttransplant samples. These mutations were absent in $93 \%$ of the pretransplantation clones analyzed. There was a significant correlation between the development of mutations in the 'a' determinant region and the duration of HBIG therapy. Most of the mutations result in changes in predicted antigenicity of the $S$ protein. During follow-up, mutations in $14(78 \%)$ of 18 affected codons in the 'a' determinant region reverted back to the pretransplantation sequences; only 1 codon had a de novo change after the withdrawal of HBIG. Two control patients who did not receive HBIG had no change in the 'a' determinant in their posttransplantation samples. These data support the hypothesis that mutations in the $S$ gene were induced or selected by immune pressure exerted by HBIG. HBV S mutants may play a role in HBV reinfection in liver transplant recipients who received HBIG prophylaxis. (HEPATOLOGY 1998;27:213222.)

Abbreviations: OLT, orthotopic liver transplantation; HBV, hepatitis B virus; HBIG, hepatitis B immune globulin; HBsAg, hepatitis B surface antigen; anti-HBs, hepatitis B surface antibody; PCR, polymerase chain reaction.

From the ${ }^{1}$ University of Michigan and VA Medical Center, Ann Arbor, MI; 2 University of California Los Angeles-C edars Sinai M edical Center, Los Angeles, CA; and ${ }^{3} \mathrm{C}$ alifornia Pacific Medical Center, San Francisco, CA

Received April 29, 1997; accepted August 19, 1997.

This article was published in abstract form in HEPATOLOGY 1995;22:150A and $1996 ; 24: 182 \mathrm{~A}$.

Supported by the VA Merit Review Award and Thomas H. C. Cheung Foundation (to A.S.F.L.), and NIH:M01-RR00042 to the General Clinical Research Center at the University of Michigan.

Address reprint requests to: Anna S. F. Lok, M.D., University of Michigan Medical Center, Division of Gastroenterology, 3912 Taubman Center, Box 0362, Ann Arbor, MI 48109. Fax: (313) 936-7392.

Copyright (1) 1998 by the American Association for the Study of Liver Diseases.

0270-9139/98/2701-0033\$3.00/0
Early studies found that orthotopic liver transplantation (OLT) for hepatitis B virus (HBV)-related liver failure was associated with a very high rate of reinfection and severe and rapidly progressive liver disease, resulting in a significant decrease in graft and patient survival compared with patients transplanted for other causes of liver disease. ${ }^{1,2}$ Various measures have been tried in an attempt to reduce the rate of reinfection. The most promising results have come from the use of long-term ( $\geq 6$ months) high-dose hepatitis B immune globulin ( $\mathrm{HBIG}) .^{3,4}$ However, this regimen is expensive, and a significant reduction in the rate of reinfection is mainly seen in patients who have nonreplicative infection pre-OLT. Reinfection despite HBIG immunoprophylaxis may be caused by inadequate neutral ization of overwhelming amounts of wildtype HBV, or to breakthrough infection by immune escape mutants.

The major B-cell epitopes of hepatitis B surface antigen (HBsAg) have been shown to reside in the ' $a$ ' determinant region located at amino acid positions 124-149.5,6 This region is conformational and is thought to consist of two loops held by disulfide bridges between cysteines 124 and 137, and cysteines 138 and $147 . .^{7}$ The second loop is more conserved and confers most of the antigenicity of the ' $a$ ' determinant; this loop is sometimes referred to as the major hydrophilic region (MHR). HBV can be classified into four major subtypes: adr, adw, ayr, and ayw. Antibodies to the 'a' determinant confer protection against all subtypes of HBV. ${ }^{8}$

Mutations in the HBV S gene have been reported in OLT recipients who developed HBV reinfection despite prophylaxis with monoclonal or polyclonal hepatitis B surface antibody (anti-HBs). McMahon et al. found amino acid substitutions in the ' $a$ ' determinant in all three patients who were reinfected despite monoclonal anti-HBs prophylaxis, ${ }^{9}$ while the incidence of mutations in the ' $a$ ' determinant in OLT recipients who were reinfected despite HBIG prophylaxis varied from $0 \%$ to $33 \% .^{10-12}$ Some of these mutations, including the glycine-to-arginine substitution at codon 145, have been shown to decrease binding to monoclonal anti$\mathrm{HBs}$, suggesting that the breakthrough infections were caused by immune escape mutants. $9,11,13$ The number of patients cited in the above studies ranged from three to seven patients; therefore, the significance of $S$ escape mutants in HBV reinfection post-OLT remains unclear. It is also possible that additional mutations may be present in the HBV $\mathrm{S}$ gene outside the ' $a$ ' determinant in patients who received polyclonal anti-HBs (HBIG). Unfortunately, there are very few data on the sequence in the rest of the $S$ gene. In addition, to date, there are no data on the reversibility of these mutations after withdrawal of HBIG therapy. 
The aims of this study were to determine: 1) the preval ence of HBV S gene mutations in patients who developed HBV reinfection after OLT despite HBIG prophylaxis; 2) the correlation between the development of HBV S gene mutations post-OLT and the dose and duration of HBIG therapy; 3 ) the effect of these mutations on the predicted antigenicity of HBsAg; and 4) the reversibility of these mutations after withdrawal of HBIG therapy.

\section{PATIENTS AND METHODS}

Patients. Twenty patients who underwent OLT for HBsAg-positive liver failure at the Cedars-Sinai Medical Center in Los Angeles and the California Pacific M edical Center in San Francisco between 1989 and 1994 were studied. They represented consecutive patients who were reinfected despite HBIG prophylaxis at these two centers. Eighteen patients transplanted during this same period were not reinfected. Reinfection was defined as reappearance of HBsAg in serum. The 20 study patients included 18 males and 2 females, with a mean age of $45 \pm 2$ years (range, 31-64 years) (Table 1). The indications for OLT were end-stage cirrhosis in 18 patients and fulminant hepatic failure in 2 patients. Eleven (55\%) patients were positive for serum HBV DNA by liquid hybridization assay before OLT. Five patients were positive for hepatitis D virus antibody before OLT.

Thirteen patients (patients 1-13) became HBsAg-positive again while they were still receiving HBIG; 7 (patients 14-20) became $\mathrm{HBsAg}$-positive after discontinuation of HBIG. Reinfection occurred after a mean of $8.5 \pm 1.5$ months (range, 1-20 months) post-OLT. The 7 patients who were reinfected after discontinuation of HBIG were scheduled to receive HBIG for a finite period per protocol (mean, $8 \pm 2$ months; range, anhepatic phase only to 12 months). Reinfection occurred after a mean of $7 \pm 1$ months (range, 3-11 months) after discontinuation of HBIG therapy. All the patients received 10,000 U HBIG intravenously during the anhepatic phase, followed by $3,000 \mathrm{U}$ intravenously daily during the first week, and then $1,000 \mathrm{U}$ intramuscularly every 1 to 4 weeks to maintain anti-HBs levels $\geq 100 \mathrm{IU} / \mathrm{L} .{ }^{14}$

All the patients received antirejection therapy that consisted of prednisone and cyclosporine with or without azathioprine. Four patients died from liver failure secondary to recurrent HBV-related liver disease, and 1 died from disseminated tuberculosis $16 \pm 3$ months after OLT (range, 10-29 months) (Table 1). Fifteen patients are still alive $31 \pm 4$ months (range, $6-53$ months) after OLT. Two had established cirrhosis, while the other 13 had chronic hepatitis on liver biopsy.

Two patients who were reinfected 1 and 2 months after OLT during the pre-HBIG era served as untreated controls.

Materials. Residual stored (at $-70^{\circ} \mathrm{C}$ ) sera collected during each clinic visit were retrieved. Paired sera pre-(collected at the time of OLT or within 6 months before OLT) and post- (at the time of reappearance of $\mathrm{HBSAg}$ ) OLT from each patient were studied. In addition, follow-up sera were available for testing in 12 patients. The follow-up sera were collected $20 \pm 4$ months after discontinuation of HBIG in the 9 patients who were still alive, and after 5, 6, and 10 months in the 3 patients who had died.

Methods. HBsAg, anti-HBs, and antibodies to hepatitis D virus were tested by commercially available enzyme immunoassay kits (Auszyme monoclonal, Ausab, and Anti-delta, Abbott Laboratories, North Chicago, IL).

Serum HBV-DNA Assay. Pre-OLT sera were tested for serum HBV DNA by a liquid hybridization assay (Genostics, Abbott Laboratories).

DNA Extraction, Polymerase Chain Reaction, and Sequencing of HBV S Gene. Protein in serum was digested by incubating $100 \mu \mathrm{L}$ serum in a buffer solution containing (final concentration) $500 \mu \mathrm{g} / \mathrm{mL}$ proteinase $\mathrm{K}, 10 \mathrm{mmol} / \mathrm{L}$ TRIS- $\mathrm{HCl}(\mathrm{pH} 8.0), 20 \mathrm{mmol} / \mathrm{L}$ ethylenediaminetetraacetic acid, $0.5 \%$ sodium dodecyl sulfate, and $1 \mu \mathrm{mol} / \mathrm{L}$
$\mathrm{CaCl}_{2}$ at $50^{\circ} \mathrm{C}$ for 2 hours. Serum protein was removed using QIAquick spin columns (Qiagen Inc., Chatsworth, CA) according to the manufacturer's instructions. The purified DNA was eluted with $50 \mu \mathrm{L}$ of $10 \mathrm{mmol} / \mathrm{L}$ TRIS- $\mathrm{HCl}$ (pH 8.5), and used for polymerase chain reaction (PCR) amplification. Nested PCR was performed using primers flanking the entire $S$ gene. For the first-round $P C R, 5$ $\mu \mathrm{L}$ of DNA was used in a reaction volume of $50 \mu \mathrm{L}$ consisting of 10 $\mathrm{mmol} / \mathrm{L} \mathrm{Tris-HCl}$ (pH 8.3), $50 \mathrm{mmol} / \mathrm{L} \mathrm{KCl}, 1.5 \mathrm{mmol} / \mathrm{L} \mathrm{MgCl}_{2}, 250$ $\mu \mathrm{mol} / \mathrm{L}$ of each dNTP, $0.3 \mu \mathrm{mol} / \mathrm{L}$ sense primer SS1 (5'-TTGGGGTGGAGCCCTCA-3', positions 3070-3086), $0.3 \mu \mathrm{mol} / \mathrm{L}$ antisense primer SAS1 (5'-GCAAAGCCCAAAAGACCCAC-3', positions 10191000 ), and 2.5 units of Taq polymerase (Amplitaq, Perkin-Elmer Corp., Foster City, CA). For the second-round PCR, $1 \mu \mathrm{L}$ of the first-round product was added to the same buffer, except that 0.6 $\mu \mathrm{mol} / \mathrm{L}$ of each of the internal primers SS2 (5'-TGGTGGCTCCAGTTC - 3 ', positions 61-75) and SAS2 (5'-GACATACTTTCCAATCAATAGG-3', positions 991-970) were used. The reactions were performed in a Personal Cycler (Biometra Inc., Tampa, $\mathrm{FL}$ ) with an initial denaturation step at $95^{\circ} \mathrm{C}$ for 2 minutes and 38 cycles at $94^{\circ} \mathrm{C}$ for 1 minute, $56^{\circ} \mathrm{C}$ (for first round, and $51^{\circ} \mathrm{C}$ for second round) for 1 minute, and $72^{\circ} \mathrm{C}$ for 3 minutes; and a final extension step at $72^{\circ} \mathrm{C}$ for 7 minutes. Five microliters of the second-round PCR product was run through a 1.5\% agarose gel, stained with ethidium bromide, and examined with an ultraviolet transilluminator. Samples that were PCR-positive were purified using QIAquick spin columns. Purified HBV DNA was sequenced either manually with Sequenase version 2.0 kits (Amersham Corp., Arlington Heights, IL) according to the manufacturer's instructions, or by the DNA Sequencing Core Facility at the University of Michigan Medical Center using the standard protocol for the Applied Biosystems DNA sequencer 373A (Perkin-Elmer Corp.). SS2, SAS2, SS3 (5'-CATCTTCTTGTTGGTTCTTCT-3', positions 427-447), and SAS3 (5'-CCCCCAATACCACATCATCCA-3', positions 760-740) were used as sequencing primers. Each sample was sequenced bidirectionally using PCR products from two independent reactions.

Cloning. To determine whether mutations in the ' $a$ ' determinant detected in post-OLT samples were present pre-OLT and whether they persisted after HBIG was discontinued, PCR-amplified HBV DNA from selected samples were cloned into PCR3-Uni vectors (Invitrogen Corp., San Diego, CA) following the manufacturer's directions. Briefly, first-round PCR products were amplified in a second-round reaction using the internal sense primer SS2 phosphorylated with T4 kinase and antisense primer SAS2. Ligation was performed at $14^{\circ} \mathrm{C}$ overnight. TOP10F'-competent Escherichia coli cells (Invitrogen Corp.) were used for transformation. Transformed bacteria were selected by plating on Luria-Bertoni agar in the presence of ampicillin at $100 \mu \mathrm{g} / \mathrm{mL}$. Single colonies were replicated onto duplicate Luria-Bertoni-ampicillin agar plates. One set of duplicate plates was screened by colony blot hybridization on nylon membranes (NEN Research Products, Boston, MA) according to the manufacturer's directions to detect clones containing the HBV S gene insert. The hybridization probe was derived from a T7 RNA transcript of a previously sequenced HBV S gene inserted into pCR3-Uni labeled with ${ }^{32}$ P-dUTP (Amersham Corp.). Clones that were positive for HBV S gene were grown overnight in Luria-Bertoni broth containing $50 \mu \mathrm{g} / \mathrm{mL}$ ampicillin. Recombinant plasmids were recovered by standard alkaline lysis miniprep procedures. Purified plasmids were digested with the restriction enzymes Hind III and EcoRI. Plasmids that contained only one insert of the HBV S gene were used for sequencing with primers SS3 and SAS3.

Antigenicity Plots. To determine whether the changes in amino acid sequences of the HBV $S$ gene in the post-OLT samples alter the predicted antigenicity of the HBV S protein, antigenicity plots of the entire HBV $S$ gene sequences in paired pre and post-OLT samples from each patient were performed using MacVector 5.0.1 (Oxford Molecular, Oxford, England). The antigenic index combines information from hydrophilicity, surface probability, and backbone flexibility predictions, along with the secondary structure predictions based 
TABLE 1. Changes in Amino Acid Sequences of the HBV S Gene Between Pre- and Post-OLT Sera in Relation to the Dose and Duration of HBIG Therapy

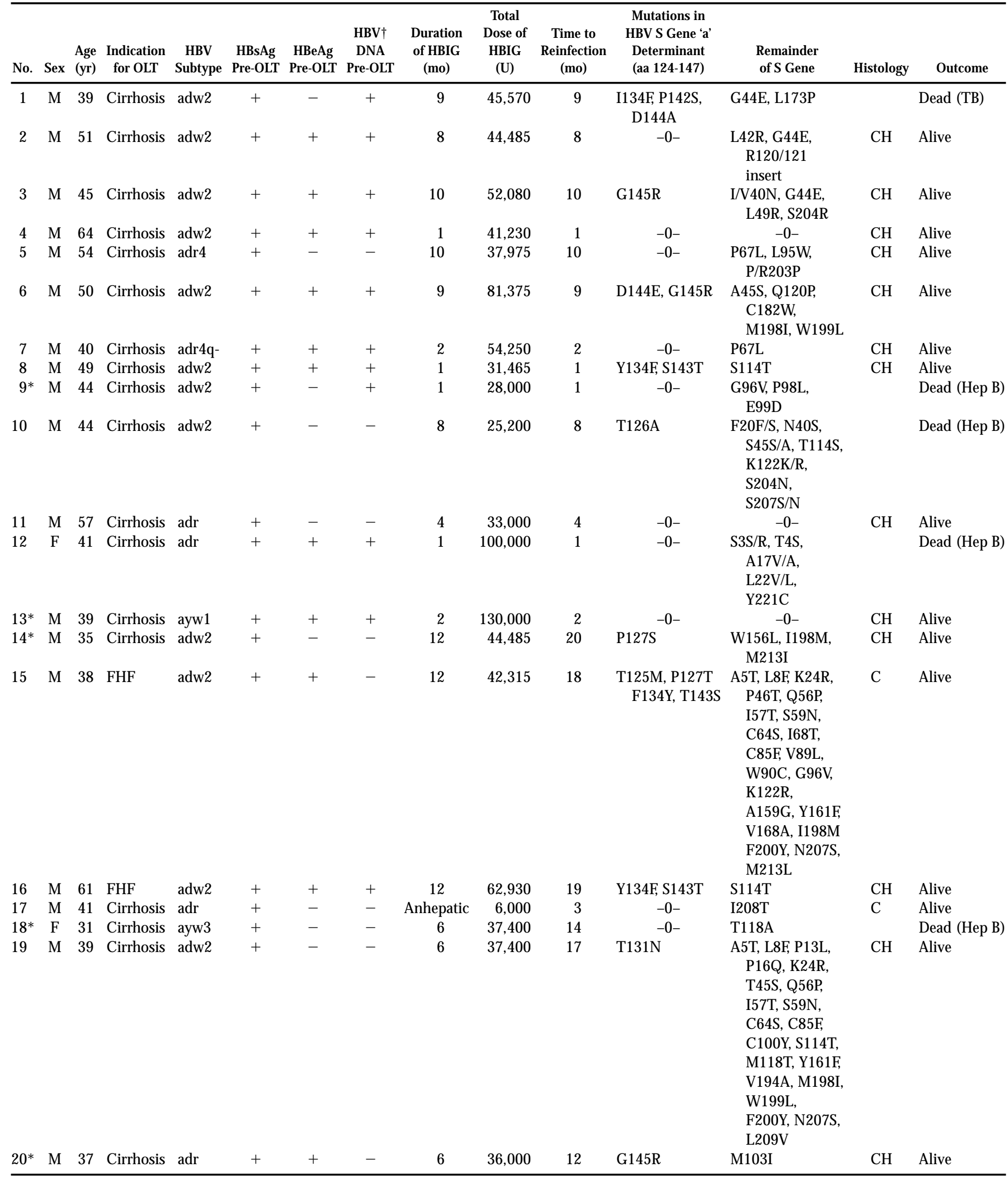

Abbreviations: $F H F$, fulminant hepatic failure; $\mathrm{CH}$, chronic hepatitis; $C$, cirrhosis; $A$, alanine; $C$, cysteine; $D$, aspartic acid; $E$, glutamic acid; $F$, phenylalanine; $G$, glycine; $H$, histidine; I, isoleucine; $K$, Iysine; L, leucine; $M$, methionine; $N$, asparagine; $P$, proline; $Q$, glutamine; $R$, arginine; $S$, serine; $T$, threonine; $V$, valine; $W$, tryptophan; $Y$, tyrosine.

*Anti-hepatitis D virus.

†Tested by liquid hybridization assay. 
on Chou-Fasman and Robson-Garner. ${ }^{15}$ The antigenic index: $\mathrm{S}(0.3$ hydro [i] +0.15 surf-prob[i] +0.15 flex [i] +0.2 chou-fas [i] +0.2 rob-garn[i]) was determined using the hydrophilicity method of Hopp and Woods with the hydrophilicity window set to 6 .

Statistical Analyses. Statistical analyses were performed using the Mann-Whitney test for comparison of continuous variables and Fisher's Exact test for comparison of proportions between groups.

\section{RESULTS}

All 20 paired pre and post-OLT samples from the study patients were HBV-DNA-positive by PCR assay, even though the pre-OLT samples from 9 patients were HBV-DNAnegative by liquid hybridization assay (Table 1). Comparison of the pre-OLT sequences of the 20 patients with 88 published sequences ${ }^{16}$ showed that the predominant HBV genotype and subtype were A ( 9 patients) and adw2 (12 patients), respectively. Mutations were defined as rare if they were present in 1 to 2 , and unique if they were absent in the 88 published sequences.
Frequency and D istribution of Amino Acid Changes in the $\mathbf{S}$ Gene Post-OLT. The sequences of the pre- and post-OLT samples from each patient were compared to identify the nucleotide and amino acid changes in the $S$ gene that were detected post-OLT (Table 1). Ten (50\%) patients ( 5 were reinfected while still receiving $\mathrm{HBIG}$, and 5 after $\mathrm{HBIG}$ was discontinued) had 18 amino acid substitutions involving the ' $a$ ' determinant in the post-OLT samples; all 10 had additional amino acid changes in the rest of the $S$ gene. Among the 18 changes in the ' $a$ ' determinant, 9 (50\%) involved the first loop; of these 9 amino acid substitutions, 6 may represent subtypic changes (125 threonine-methionine, 127 prolinethreonine, 131 threonine-asparagine, and 134 phenylalaninetyrosine), 1 was rare (126 threonine-alanine), 1 was unique (127 proline-serine), and the remaining 1 was a reversion from a unique to a common amino acid (134 isoleucinephenylalanine) (Table 2). The other 9 (50\%) changes in the ' $a$ ' determinant were clustered around codons 142-145 of the second loop (M HR); 3 amino acid substitutions at codon 143

TABLE 2. Changes in the Nucleotide and Amino Acid Sequences in the 'a' Determinant and Immediately Upstream Region of the HBV S Gene Between Pre- and Post-OLT Samples

\begin{tabular}{|c|c|c|c|c|c|c|c|c|c|c|c|c|c|c|c|c|c|c|c|c|c|c|c|c|c|c|c|c|}
\hline adw2 & $\begin{array}{c}120 \\
P \\
\text { CCA }\end{array}$ & $\begin{array}{c}121 \\
\text { C } \\
\text { TGC }\end{array}$ & $\begin{array}{c}122 \\
\text { K } \\
\text { AAA }\end{array}$ & $\begin{array}{c}123 \\
T \\
\text { ACC }\end{array}$ & $\begin{array}{c}124 \\
\text { C } \\
\text { TGC }\end{array}$ & $\begin{array}{c}125 \\
T \\
\text { ACG }\end{array}$ & $\begin{array}{c}126 \\
\mathrm{~T} \\
\mathrm{ACT}\end{array}$ & $\begin{array}{c}127 \\
P \\
\text { CCT }\end{array}$ & $\begin{array}{c}128 \\
\text { A } \\
\text { GCT }\end{array}$ & $\begin{array}{c}129 \\
Q \\
\text { CAA }\end{array}$ & $\begin{array}{c}130 \\
\text { G } \\
\text { GGC }\end{array}$ & $\begin{array}{c}131 \\
\mathrm{~N} \\
\text { AAC }\end{array}$ & $\begin{array}{c}132 \\
\mathrm{~S} \\
\mathrm{TCT}\end{array}$ & $\begin{array}{c}133 \\
\text { M } \\
\text { ATG }\end{array}$ & $\begin{array}{c}134 \\
F \\
\text { TTT }\end{array}$ & $\begin{array}{c}135 \\
P \\
\text { CCC }\end{array}$ & $\begin{array}{c}136 \\
\mathrm{~S} \\
\text { TCA }\end{array}$ & $\begin{array}{c}137 \\
\text { C } \\
\text { TGT }\end{array}$ & $\begin{array}{c}138 \\
\text { C } \\
\text { TGC }\end{array}$ & $\begin{array}{c}139 \\
\text { C } \\
\text { TGT }\end{array}$ & $\begin{array}{c}140 \\
T \\
\text { ACA }\end{array}$ & $\begin{array}{c}141 \\
K \\
\text { AAA }\end{array}$ & $\begin{array}{c}142 \\
P \\
\text { CCT }\end{array}$ & $\begin{array}{c}143 \\
\quad \mathrm{~T} \\
\text { ACG }\end{array}$ & $\begin{array}{c}144 \\
\text { D } \\
\text { GAT }\end{array}$ & $\begin{array}{c}145 \\
\text { G } \\
\text { GGA }\end{array}$ & $\begin{array}{c}146 \\
N \\
\text { AAT }\end{array}$ & $\begin{array}{c}147 \\
C \\
\text { TGC }\end{array}$ \\
\hline & & & $\mathrm{R}$ & & & $M$ & 1 & $\begin{array}{l}\mathrm{T} \\
\mathrm{L}\end{array}$ & & & & $T$ & & & $Y$ & & & & & & $\mathrm{~S}$ & & & $\mathrm{~S}$ & & & & \\
\hline la & - & - & - & - & - & - & - & - & - & - & - & - & - & - & $\begin{array}{c}\text { I } \\
\text { ATT }\end{array}$ & - & - & - & - & - & - & - & $\begin{array}{c}P \\
C C T\end{array}$ & - & $\begin{array}{c}\mathrm{D} \\
\mathrm{GAT}\end{array}$ & - & - & - \\
\hline$b$ & - & - & - & - & - & - & - & - & - & - & - & - & - & - & $\begin{array}{c}\mathrm{F} \\
\text { TTT }\end{array}$ & - & - & - & - & - & - & - & $\begin{array}{c}\mathrm{S} \\
\mathrm{TCT}\end{array}$ & - & $\begin{array}{c}\mathrm{A} \\
\mathrm{GCT}\end{array}$ & - & - & - \\
\hline $2 a$ & - & - & - & - & - & - & - & - & - & - & - & - & - & - & - & - & - & - & - & - & - & - & - & - & - & - & - & - \\
\hline b & - & ${ }^{R}$ AGA & - & - & - & - & - & - & - & - & - & - & - & - & - & - & - & - & - & - & - & - & - & - & - & - & - & - \\
\hline $3 a$ & - & - & - & - & - & - & - & - & - & - & - & - & - & - & - & - & - & - & - & - & - & - & - & - & $\overline{\mathrm{GAT}}$ & $\underset{G G A}{G}$ & - & - \\
\hline$b$ & - & - & - & - & - & - & - & - & - & - & - & - & - & - & - & - & - & - & - & - & - & - & - & - & $\overline{\mathrm{GAC}}$ & $\begin{array}{c}\mathrm{R} \\
\mathrm{AGA}\end{array}$ & - & - \\
\hline $6 a$ & $\begin{array}{c}Q \\
\text { CAA }\end{array}$ & - & - & - & - & - & - & - & - & - & - & - & - & - & - & - & - & - & - & - & - & - & - & - & $\begin{array}{c}\text { D } \\
\text { GAT }\end{array}$ & $\underset{\mathrm{GGA}}{\mathrm{G}}$ & - & - \\
\hline b & $\begin{array}{c}P \\
C C A\end{array}$ & - & - & - & - & - & - & - & - & - & - & - & - & - & - & - & - & - & - & - & - & - & - & - & $\begin{array}{c}\mathrm{E} \\
\mathrm{GAG}\end{array}$ & $\begin{array}{c}\mathrm{R} \\
\mathrm{AGA}\end{array}$ & - & - \\
\hline $8 a$ & - & - & - & - & - & - & - & - & - & - & - & - & - & - & $\begin{array}{c}\mathrm{Y} \\
\text { TAT }\end{array}$ & - & - & - & - & - & - & - & - & $\begin{array}{c}\mathrm{S} \\
\mathrm{TCG}\end{array}$ & - & - & - & - \\
\hline$b$ & - & - & - & - & - & - & - & - & - & - & - & - & - & - & $\begin{array}{c}\mathrm{F} \\
\text { TTT }\end{array}$ & - & - & - & - & - & - & - & - & $\begin{array}{c}\mathrm{T} \\
\mathrm{ACG}\end{array}$ & - & - & - & - \\
\hline $10 a$ & - & - & $\begin{array}{c}\mathrm{K} \\
\mathrm{AAA}\end{array}$ & - & - & - & $\begin{array}{c}\mathrm{T} \\
\mathrm{ACT}\end{array}$ & - & - & - & - & - & - & - & - & - & - & - & - & - & - & - & - & - & - & - & - & - \\
\hline$b$ & - & - & $\begin{array}{c}\mathrm{K} / \mathrm{R} \\
\mathrm{ARA}^{*}\end{array}$ & - & - & - & $\begin{array}{c}\mathrm{A} \\
\mathrm{GCT}\end{array}$ & - & - & - & - & - & - & - & - & - & - & - & - & - & - & - & - & - & - & - & - & - \\
\hline $14 a$ & - & - & - & - & - & - & - & $\begin{array}{c}P \\
C C T\end{array}$ & - & - & - & - & - & - & - & - & - & - & - & - & - & - & - & - & - & - & - & - \\
\hline$b$ & - & - & - & - & - & - & - & $\begin{array}{c}\mathrm{S} \\
\mathrm{TCT}\end{array}$ & - & - & - & - & - & - & - & - & - & - & - & - & - & - & - & - & - & - & - & - \\
\hline $15 a$ & - & - & $\begin{array}{c}\mathrm{K} \\
\mathrm{AAA}\end{array}$ & - & - & $\begin{array}{c}\mathrm{T} \\
\mathrm{ACA}\end{array}$ & - & $\begin{array}{c}\mathrm{P} \\
\mathrm{CCT}\end{array}$ & - & - & - & - & - & - & $\begin{array}{c}\mathrm{F} \\
\text { TTT }\end{array}$ & - & - & - & - & - & - & - & - & $\begin{array}{c}\mathrm{T} \\
\mathrm{ACG}\end{array}$ & - & - & - & - \\
\hline b & - & - & $\begin{array}{c}\mathrm{R} \\
\mathrm{CGA}\end{array}$ & - & - & $\begin{array}{c}\text { M } \\
\text { ATG }\end{array}$ & - & $\begin{array}{c}\mathrm{T} \\
\mathrm{ACT}\end{array}$ & - & - & - & - & - & - & $\begin{array}{c}\text { Y } \\
\text { TAT }\end{array}$ & - & - & - & - & - & - & - & - & $\begin{array}{c}\mathrm{S} \\
\mathrm{TCG}\end{array}$ & - & - & - & - \\
\hline $16 a$ & - & - & - & - & - & - & - & - & - & - & - & - & - & - & $\begin{array}{c}\text { Y } \\
\text { TAT }\end{array}$ & - & - & - & - & - & - & - & - & $\begin{array}{c}\mathrm{S} \\
\mathrm{TCG}\end{array}$ & - & - & - & - \\
\hline b & - & - & - & - & - & - & - & - & - & - & - & - & - & - & $\begin{array}{c}\mathrm{F} \\
\text { TTT }\end{array}$ & - & - & - & - & - & - & - & - & $\begin{array}{c}\mathrm{T} \\
\mathrm{ACG}\end{array}$ & - & - & - & - \\
\hline 19a & - & - & - & - & - & - & - & - & - & - & - & $\begin{array}{c}\mathrm{T} \\
\mathrm{ACC}\end{array}$ & - & - & - & - & - & - & - & - & - & - & - & - & - & - & - & - \\
\hline$b$ & - & - & - & - & - & - & - & - & - & - & - & $\begin{array}{c}\mathrm{N} \\
\mathrm{AAC}\end{array}$ & - & - & - & - & - & - & - & - & - & - & - & - & - & - & - & - \\
\hline $20 a$ & - & - & - & - & - & - & - & - & - & - & - & - & - & - & - & - & - & - & - & - & - & - & - & - & $\overline{\mathrm{GAC}}$ & $\underset{G G A}{G}$ & - & - \\
\hline b & - & - & - & - & - & - & - & - & - & - & - & - & - & - & - & - & - & - & - & - & - & - & - & - & $\overline{\mathrm{GAC}}$ & $\begin{array}{c}\mathrm{R} \\
\mathrm{AGA}\end{array}$ & - & - \\
\hline
\end{tabular}

NOTE. The amino acid and nucleotide sequences for HBV genotype B subtype adw2 are listed at the top; amino acid substitutions that are found in other genotypes and subtypes are indicated. Positions in which the pre- and post-OLT sequences are identical are represented by a dash (-). 
may represent subtypic changes, the 144 aspartic acid-toalanine substitution was a rare change, but the 5 substitutions affecting codons 142, 144, and 145 were unique (142 proline-serine, 144 aspartic acid-glutamic acid, and 145 glycine-arginine) (Table 2). Three of these 10 patients had additional changes just upstream of the ' $a$ ' determinant. One patient (patient 6) had an amino acid substitution involving codon 120 (glutamine-proline), and 2 patients (patients 10 and 15) had amino acid substitutions involving codon 122 (lysine-arginine) that may change the subtypic determinant from ' $d$ ' to ' $y$.' 17

Seven (35\%) patients had changes in the $S$ gene that were entirely outside the ' $a$ ' determinant (Table 1); of these, one (patient 2) had an amino acid insertion between codons 120 and 121 , just upstream of the 'a' determinant. Three patients (patients 4, 11, and 13) had identical sequences of the entires gene in the pre- and post-OLT samples (Table 1 ).

In total, 17 (85\%) patients had one or more amino acid changes in the $S$ gene post-OLT. The mean number of amino acid substitutions for the entire $S$ gene was $5.9 \pm 1.7$ (median, 3; range, 1-25). The mean ratio of amino acid substitutions to the number of codons was 0.075 for the ' $a$ ' determinant and 0.024 for the rest of the $S$ gene $(P=.005)$; the mean value for the latter ratio decreased to $0.014(\mathrm{P}=$ .001 ) if patients 15 and 19 were excluded (see below). Thus, apart from patients 15 and 19 , mutations in the $S$ gene outside the ' $a$ ' determinant were infrequent and tended to cluster around codons 40-45, 114-122, and 198-208 (Fig. 1).

Patient 15 had a total of 25 amino acid changes in the entire $S$ gene between the pre- and post-OLT samples (Table $1)$. All of these changes led to a switch from genotype $B$, subtype adw2, to genotype D, subtype ayw3.16,17 Patient 19 had 22 amino acid changes between the pre- and post-OLT samples; 19 of these changes led to a switch from genotype $B$ to genotype $A$, but the subtype remained as adw2 (Table 1 ). Interestingly, of the 12 patients whose pre-OLT sequences were closest to subtype adw2, 9 (75\%) developed mutations in the 'a' determinant post-OLT compared with only 1
(12.5\%) of 8 patients whose pre-OLT sequences were closest to other subtypes $(P=.02)$ (Table 1$)$.

The two controls had no change in the 'a' determinant in the post-OLT samples.

F requency of Amino Acid Substitutions in Relation to Duration and D ose of HBIG Therapy. The amino acid substitutions in patients 15 and 19 may have been caused by superinfection with HBV of other genotypes/subtypes or selection from a mixed infection rather than widespread point mutations. Thus, they were excluded from the following analyses. Nine (50\%) patients were found to have mutations involving the ' $a$ ' determinant or the immediate upstream region (codons 120-147). Patients who received HBIG for 6 months or longer were significantly more likely to develop mutations in this region (8 of $10[80 \%]$ ) than those who received HBIG for shorter durations ( 1 of $8[13 \%])(P=.02)$. There was no difference in the mean total dose of HBIG received between patients with and those without mutations involving the ' $a$ ' determinant $(47,000 \pm 6,400 \mathrm{U}$ [ range, 25,200-81,375 U] vs. $52,000 \pm 12,900 \cup$ [range, 6,000-130,000 U], respectively) ( $P=$ not significant).

D etection of Post-OLT Changes in Pre-0LT Clones. Seven of the 11 patients who had amino acid changes in the 'a' determinant or immediately upstream region were randomly selected for cloning to determine if the changes detected in the post-OLT samples were present as minor species before OLT. Ten clones were obtained from the pre-OLT samples from 5 patients, and 8 clones were obtained from the other 2 patients. Of the 66 clones sequenced, only 5 clones ( 2 from patient 1, 2 from patient 6 , and 1 from patient 15) had one of the amino acid changes that were detected post-OLT (Table $3)$. With the possible exception of the glutamine-to-proline substitution at codon 120, these changes would not be predicted to have a significant effect on antigenicity.

Changes in Predicted Antigenicity of the Major S Protein. To determine the effect of amino acid changes post-OLT on the predicted antigenicity of the ' $a$ ' determinant and the major B-cell epitopes of the major S protein, we arbitrarily divided
FIG. 1. Distribution of amino acid substitutions in the HBV S gene in the post-OLT samples.

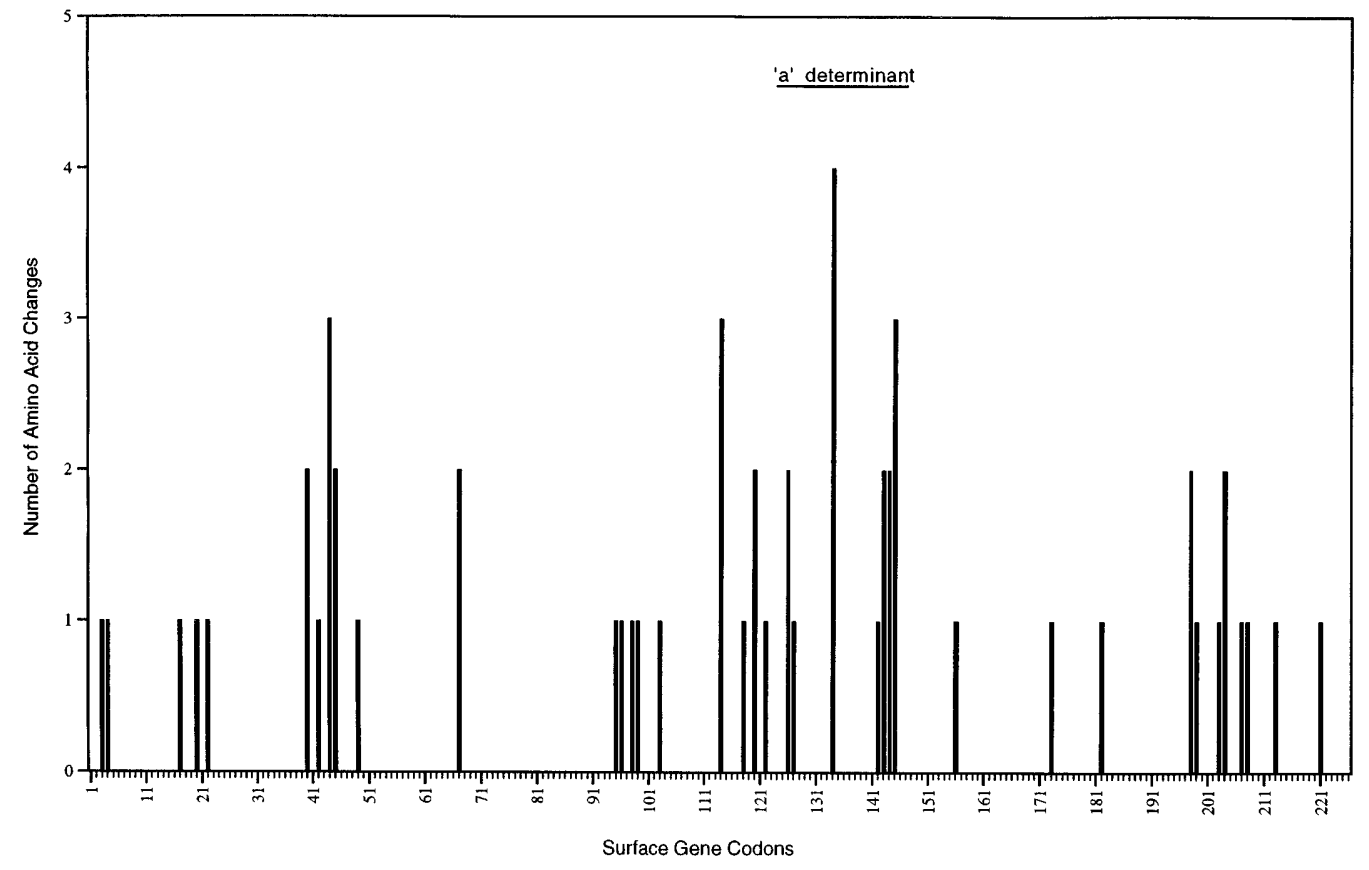


TABLE 3. Detection of HBV S Gene Mutations in Pre-0LT Samples

\begin{tabular}{cccc}
\hline & Post-0LT Sample & \multicolumn{2}{c}{ Pre-0LT Sample } \\
\cline { 3 - 4 } $\begin{array}{c}\text { Patient } \\
\text { No. }\end{array}$ & $\begin{array}{c}\text { No. of } \\
\text { Clones } \\
\text { Exino Acid Changes }\end{array}$ & $\begin{array}{c}\text { No. of Clones } \\
\text { With Amino } \\
\text { Acid Changes }\end{array}$ \\
\hline 1 & I 134 F & 10 & 2 \\
& P 142 S & & 0 \\
2 & D 144 A & 10 & 0 \\
3 & R 120/121 & 10 & 0 \\
6 & G 145 R & 8 & 0 \\
& Q 120 P & & 2 \\
10 & D 144 E & 10 & 0 \\
15 & G 145 R & & 0 \\
& K 122 R & 8 & 0 \\
& T 126 A & & 0 \\
& K 122 R & & 0 \\
& T 125 M & & 1 \\
& P 127 T & 10 & 0 \\
\hline
\end{tabular}

the region spanning amino acids $110-160$ into four domains: I (codons 110-123), II (codons 124-137), III (codons 138147), and IV (codons 148-160), which represent the upstream region, first and second loops of the predicted secondary structure of the 'a' determinant, and the downstream region. In most patients, the observed amino acid changes resulted in changes in the predicted antigenic index of their respective domains (Table 4, Fig. 2). However, the same mutation can induce different changes in predicted antigenicity depending on the rest of the $S$ gene sequence, as is evident in patients 3 and 20. Interestingly, the glycine-toarginine substitution at codon 145 produced more marked changes in predicted antigenic index in the downstream region than in the second loop of the 'a' determinant.

Reversibility of the Mutations in the ' $a$ ' Determinant Region. Of the 12 patients in whom follow-up samples were available, 7 (patients 1, 3, 6, 8, 15, 16, and 20) had changes in the ' $a$ ' determinant region in the post-OLT samples (Table 5). Direct sequencing of the follow-up samples showed that 6 of these 7 patients had reversal of some or all of the mutations, including the glycine-to-arginine substitution at codon 145. The other patient (patient 3) had one mutation only (145 glycine-arginine) in the post-OLT sample that persisted in the follow-up sample, which was collected 5 months after discontinuation of HBIG, shortly before he died. The follow-up samples in the 2 patients (patients 6 and 20) who had reversal of the 145 glycine-arginine substitution were collected 9 and 24 months after discontinuation of HBIG. Three new amino acid substitutions were detected in these 7 patients: 144 alanine-glycine in patient 1,120 prolinethreonine in patient 6 , and 126 isoleucine-threonine in patient 20. In total, mutations in 14 (78\%) of 18 affected codons in the ' $a$ ' determinant region reverted to the pre-OLT sequences during follow-up; new sequences appeared in 3 codons, at least 2 of which were not de novo changes (see below), and only 1 codon retained the mutant sequence.

One additional patient (patient 2) had insertion of an arginine between codons 121 and 122 in the post-OLT sample that persisted in the follow-up sample. Four patients (patients 4, 9, 12, and 13) did not have any changes in the ' $a$ ' determinant, and immediately upstream region (codons 120149) in the post-OLT samples, no new change was detected in this region in the follow-up samples.

To determine if reversibility of mutations was related to the heterogeneity of the post-OLT sequences and if the new amino acid substitutions detected in the follow-up samples were de novo changes, serial samples from 5 of the 8 patients who had changes in the ' $a$ ' determinant and immediately upstream region were cloned and sequenced. Although 50 $(98 \%)$ of the 51 clones from the post-OLT samples had the mutant sequences, direct sequencing found that $8(67 \%)$ of 12 mutations had reversed to the pre-OLT sequences in the follow-up samples. N ew sequences were detected in 2 codons (codon 120 in patient 6 and codon 126 in patient 20), but these sequences were present as minor species in the pre-OLT samples, indicating that they were not de novo changes. The remaining 2 mutations (121/122 insertion in patient 2 and 145 glycine-arginine in patient 3) persisted in all 19 clones from the follow-up samples.

TABLE 4. Effect of HBV S Gene Mutations on Predicted Antigenicity of HBsAg

\begin{tabular}{|c|c|c|c|c|c|c|c|c|}
\hline \multirow{2}{*}{$\begin{array}{l}\text { Patient } \\
\text { No. }\end{array}$} & & & \multicolumn{4}{|c|}{ 'a' Determinant } & & \\
\hline & \multicolumn{2}{|c|}{$\begin{array}{l}\text { Upstream Region } \\
\text { (codons 110-123) }\end{array}$} & \multicolumn{2}{|c|}{$\begin{array}{c}\text { 1st Loop } \\
\text { (codons 124-137) }\end{array}$} & \multicolumn{2}{|c|}{$\begin{array}{c}\text { 2nd Loop } \\
\text { (codons 138-147) }\end{array}$} & \multicolumn{2}{|c|}{$\begin{array}{l}\text { Downstream Region } \\
\text { (codons 148-160) }\end{array}$} \\
\hline 1 & 0 & 0 & I134F & $+57 \%$ & $\begin{array}{l}\text { P142S } \\
\text { D144A }\end{array}$ & $+50 \%$ & 0 & 0 \\
\hline 2 & 120R121 & $+27 \%$ & 0 & 0 & 0 & 0 & 0 & 0 \\
\hline 8 & $\mathrm{~S} 114 \mathrm{~T}$ & $-40 \%$ & Y134F & $+24 \%$ & $\mathrm{~S} 143 \mathrm{~T}$ & $-4 \%$ & 0 & 0 \\
\hline 10 & T114S, K122R & $+62 \%$ & $\mathrm{~T} 126 \mathrm{~A}$ & $-37 \%$ & 0 & 0 & 0 & 0 \\
\hline 14 & 0 & $-4 \%$ & P127S & $-25 \%$ & 0 & 0 & W 156L & $-13 \%$ \\
\hline 15 & K122R & $+27 \%$ & T125M, P127T, F134Y & $-72 \%$ & T143S & $+4 \%$ & A159G & $+43 \%$ \\
\hline 16 & $\mathrm{~S} 114 \mathrm{~T}$ & $-40 \%$ & Y134F & $+24 \%$ & S143T & $-4 \%$ & 0 & 0 \\
\hline 19 & S114T, M 118T & $+55 \%$ & T131N & $+25 \%$ & 0 & 0 & 0 & $-39 \%$ \\
\hline
\end{tabular}

Abbreviations: aa, amino acid; Al, antigenic index. 

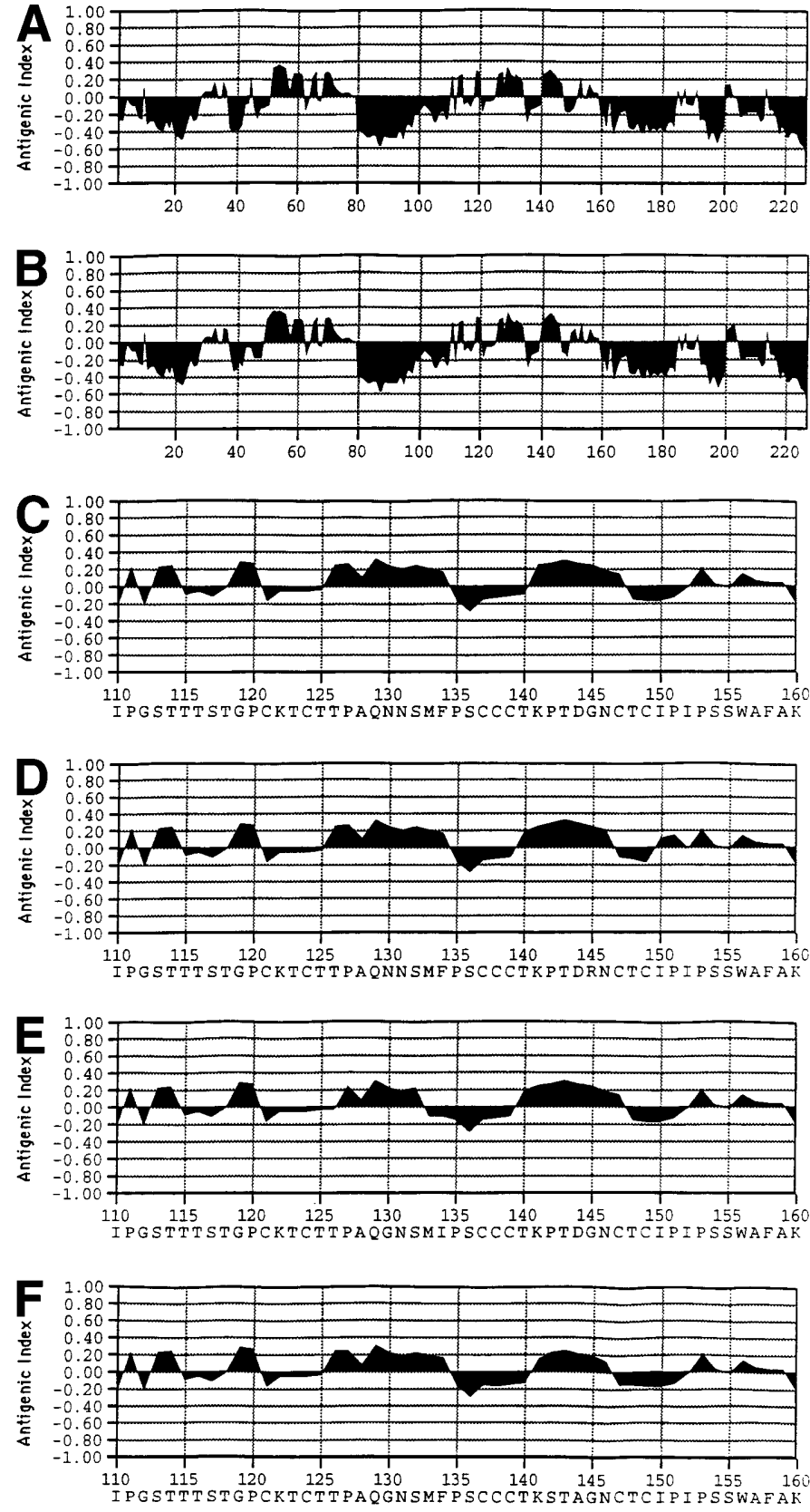

FIG. 2. Antigenicity plots based on amino acid sequences of HBsAg in paired pre- and post-OLT samples. ( $A$ and $B$ ) Antigenicity plots of the entire HBsAg of patient 3 (A) pre- and (B) posttransplant. The changes in the posttransplant sample included: G44E, I134F, P142S, D144A, and L173P. (C and D) Antigenicity plots of the 'a' determinant region of patient 3 (C) preand (D) posttransplant. The posttransplant sample had a single mutation: glycine-to-arginine substitution at codon 145 . Note that the change in antigenic index is more marked in the downstream region than in the second loop. ( $E$ and $F$ ) Antigenicity plots of the ' $a$ ' determinant region of patient 1 (E) pre- and (F) posttransplant. The posttransplant sample had mutations in both the first and second loops: I134F, P142S, and D144A

\section{DISCUSSION}

In this study, mutations in the ' $a$ ' determinant and the rest of the $S$ gene were detected in $50 \%$ and $85 \%$, respectively, of the patients who were reinfected after OLT for HBV-related liver failure despite HBIG prophylaxis. There was a significant correlation between the development of HBV S mutations and the duration of HBIG therapy, suggesting that these mutants were induced or selected by immune pressure exerted by prolonged exposure to high levels of anti-HBs. Failure to detect any of the mutations in $93 \%$ of the pre-OLT clones suggests that these mutants were completely absent or present as very minor $(<10 \%)$ species before OLT. The predominance of the mutants in the post-OLT clones and the reversion of mutations to the pre-OLT sequences after the withdrawal of HBIG provide further support that these mutations were induced or selected by HBIG. The exact reason(s) for a higher incidence of mutations in the ' $a$ ' determinant in patients infected with HBV subtype adw2 is not clear. It is possible that HBIG prepared in the United States has higher titers of antibodies against epitopes found in subtype adw2 because it is the most common subtype in this country. Since the publication of the beneficial effects of $\mathrm{HBIG}, 3,4$ it is no longer ethical to perform OLT on patients with HBsAg-related liver failure without prophylactic measures. We were only able to study paired sera from 2 patients who were transplanted in the pre-HBIG era. Both patients were reinfected shortly after OLT and had no mutations in the ' $a$ ' determinant post-OLT. Although the number of control subjects was small, these data support our hypothesis that the $\mathrm{S}$ gene mutations were induced or selected by HBIG.

Mutations were not detected in $3(15 \%)$ patients. Clearly, other factors may contribute to HBV reinfection. Patients with replicative infection pre-OLT have higher rates of reinfection despite $\mathrm{HBIG}$ therapy. Other investigators have reported that a fixed dose regimen of HBIG may be insufficient to maintain constant titers of anti-HBs in these patients. ${ }^{18}$ Two of the three patients who had no $\mathrm{S}$ mutation post-OLT were hepatitis B e antigen- and HBV-DNA-positive (by hybridization assay) pre-OLT, and were reinfected shortly after ( 1 and 2 months) transplantation. Reinfection in these patients may have occurred because of inadequate neutralization of circulating virus or release of virus from extrahepatic reservoirs.

Apart from the two patients who had a switch in HBV genotype/subtype post-OLT, mutations were concentrated in the ' $a$ ' determinant. Although the mutations were equally distributed between the two loops, mutations involving the first loop were scattered, and only 33\% were rare or unique changes. By contrast, mutations involving the second loop (MHR) clustered around codons 142-145, and the majority $(67 \%)$ were rare or unique changes (Table 2). Some of the rare or unique changes (144 aspartic acid-alanine and 145 glycine-arginine) have al so been found in newborns of carrier mothers who developed HBV infection despite prophylaxis with HBIG and vaccination.7,19-21 The glycine-to-arginine substitution at codon 145 has been shown to reduce binding to monoclonal as well as polyclonal anti-HBs. $9,11,13,22,23$ In addition, synthetic peptides with a proline-to-serine substitution at codon 142, aspartic acid-to-alanine substitution at 144, and glycine-to-arginine substitution at 145 have been shown to have reduced binding to anti-HBs compared with wild-type HBsAg. ${ }^{23}$ Thus, some of the mutants that we detected post-OLT may have been induced or selected because of their ability to escape neutralization by HBIG.

Induction or selection of antigenic variants have been reported in other viruses in response to immune pressure. ${ }^{24}$ Reversal to wild-type sequences upon removal of immune pressure is less well described. We found that $67 \%$ of the mutations reverted back to the pre-OLT sequences after 
Table 5. Serial Changes in Amino Acid Sequence in the 'a' Determinant Region Pre-OLT, Post-OLT, and During Follow-up

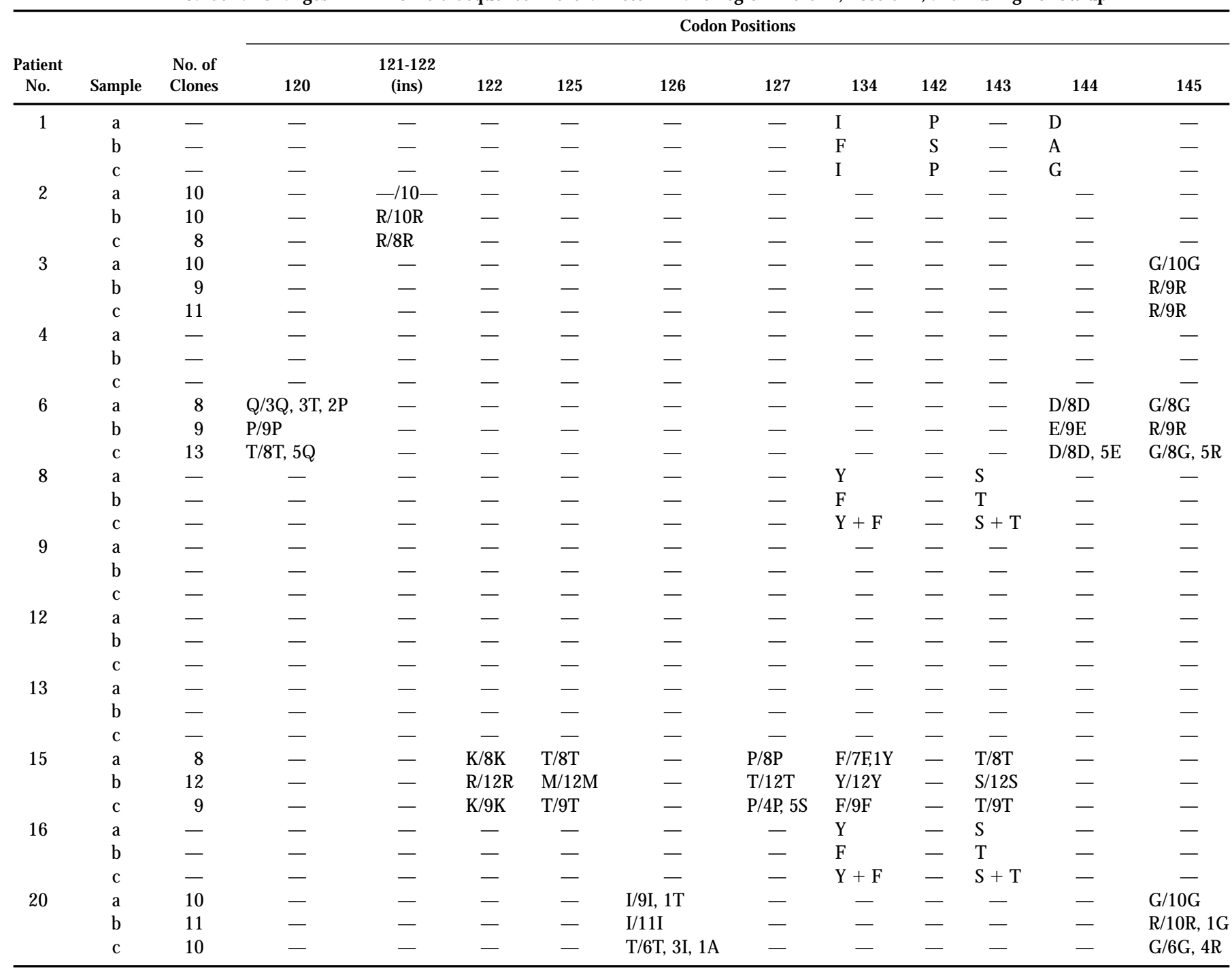

NOTE. Predominant amino acid sequence based on direct sequencing/amino acid sequence of individual clones.

withdrawal of $\mathrm{HBIG}$, suggesting that, in the absence of immune pressure, the wild-type/pre-OLT sequences have survival advantage over the mutants. N ot all of the mutations were reversed after withdrawal of $\mathrm{HBIG}$. It is not clear if persistence of some of the mutations was related to the short duration of follow-up or presence of other factors that favored the continued presence of the mutants. Of the 2 mutations that persisted (insertion arginine 120/121 in patient 2 and 145 glycine-arginine substitution in patient 3 ), the 145 glycine-arginine substitution was reversed in most of the clones analyzed in two other patients (patients 6 and 20) whose follow-up samples were collected after a longer interval from withdrawal of $\mathrm{HBIG}$, suggesting that the advantage of this mutation is lost when the immune pressure is removed. It is possible that the 145 glycine-arginine substitution might al so reverse had patient 3 lived longer.

M ost of the mutations that we detected result in changes in predicted antigenicity of the S protein. We acknowledge that our conclusion is based on mathematical modeling and may not necessarily reflect actual changes in antibody recognition. However, the formula we used takes into account multiple factors that determine antigenicity: hydrophilicity, surface probability, backbone flexibility, and predicted secondary structure. To confirm that specific epitopes were altered by the mutations, direct tests showing reduced binding to monoclonal anti-HBs are preferred. In view of the conformational nature of the HBsAg epitopes, the exact sequences necessary for the recognition of most monoclonal anti-HBs have not been precisely mapped. Waters et al. reported that mutant HBsAg with a glycine-to-arginine substitution at codon 145 failed to bind not only monoclonal antibodies RFHBs 4 and 7 that recognize the cyclical peptide 139-147, but also RFHBs1 that recognize the cyclical peptide 124137. ${ }^{13} \mathrm{C}$ arman et al. al so noted discrepancies between changes in binding to RFHBs 1 and 7 and the presence or absence of mutations in the putative recognition sites. ${ }^{12}$ We found that the same mutation can induce different changes in predicted antigenicity depending on the rest of the $S$ gene sequence (Table 4). In addition, the most significant changes in antigenic index may not be located at the site of the mutation, as in the case of the glycine-to-arginine substitution at codon 145. 
Mutations outside the ' $a$ ' determinant were uncommon, although our patients received polyclonal anti-HBs. This may be related to the fact that at least $50 \%$ of the anti-HBs that developed after recovery from acute hepatitis B or hepatitis B vaccination are directed against the ' $a$ ' determinant. ${ }^{25}$ Mutations outside the 'a' determinant tended to cluster in three regions around codons 40-45, 114-122, and 198-208. Carman et al. also noted clustering of mutations in codons 44-4912; this region has been recently shown to contain a major histocompatibility class I-restricted T-cell epitope of HBsAg. ${ }^{26}$ The second region is immediately upstream of the ' $a$ ' determinant, and changes in this region may alter the conformation of the 'a' determinant. Amino acid insertions in this region have been reported to abolish binding to antiHBs. ${ }^{27}$ The significance of the other mutation cluster region is not clear.

Mutations in the HBV S gene that disrupt the function of the overlapping $\mathrm{P}$ gene may not be tolerated. None of the mutations we detected result in premature termination of the $P$ gene. The nucleotide sequence at codon 144 can be GAT or GAC depending on the HBV genotype/subtype. A change from GGA to AGA at codon 145 that results in a glycine-toarginine substitution will create a premature stop codon (TAG) if the third nucleotide at codon 144 is T. In this study, two of the three patients who had the glycine-to-arginine substitution at codon 145 had GAT at codon 144. This mutation was tolerated because both patients had additional changes that prevent the premature termination of the $P$ gene. Patient 3 had a silent mutation from GAT to GAC, while patient 6 had a missense mutation from GAT to GAG (aspartic acid to glutamic acid). Thus, the worldwide detection of the 145 glycine-to-arginine mutation may be explained by the development of compensatory changes that permit its occurrence in all HBV genotypes in contrast to the precore stop codon mutation (A1896), which is restricted to geographical areas where the predominant HBV genotypes have $T$ at nucleotide $1858 .{ }^{28-30}$

In summary, we found that mutations in the HBV S gene, in particular the ' $a$ ' determinant, were common in OLT recipients who developed HBV reinfection despite HBIG prophylaxis. The significant correlation between the development of these mutations and the duration of HBIG therapy, the absence of these mutations pre-OLT, and the reversal of these mutations after withdrawal of HBIG suggest that these mutations were induced or selected by prolonged exposure to high levels of anti-HBs. Most of the mutations altered the predicted antigenicity of the respective domains. In addition, many of the mutations have been shown by other investigators to have reduced binding to anti-HBs. Our findings suggest that HBV S mutants that can escape neutralization by anti-HBs may play a role in $\mathrm{HBV}$ reinfection in OLT recipients who received HBIG prophylaxis. It remains to be seen whether the combination of HBIG and new antiviral compounds such as lamivudine will result in decreased frequency of HBV S mutations and whether mutants induced by one treatment will be susceptible to the other treatment.

Acknowledgment: We are grateful to Linda Brooks, R.N., for her assistance in compiling the clinical data on the patients at the California Pacific M edical Center.

\section{REFERENCES}

1. Todo S, Demetris AJ, Van Thiel D, Teperman L, Fung J, Starzl TE. Orthotopic liver transplantation for patients with hepatitis B virusrelated liver disease. HEPATOLOGY 1991;13:619-626.

2. O'Grady JG, Williams R. Liver transplantation for viral hepatitis. Br Med Bull 1990;46:481-491.

3. Samuel D, Muller R, Alexander G, Fassati L, Ducot B, Benhamou JP, Bismuth $\mathrm{H}$, et al. Liver transplantation in European patients with the hepatitis B surface antigen. N Engl J Med 1993;329:1842-1847.

4. Müller R, Gubernatis G, Farle M, N iehoff G, Klein H, Wittekind C, Tusch $\mathrm{G}$, et al. Liver transplantation in HBs antigen (HBsAg) carriers: prevention of hepatitis $B$ virus (HBV) recurrence by passive immunization. J Hepatol 1991;13:90-96.

5. Bhatnagar PK, Papas E, Blum HE, Milich DR, Nitecki D, Karels MJ, Vyas GN. Immune response to synthetic peptide analogues of $\mathrm{HBsAg}$ for the a determinant. Proc Natl Acad Sci U SA 1982;79:4400-4404.

6. Brown SE, Stanley C, Howard CR, Zuckerman AJ, Steward MW. Antibody responses to recombinant and plasma derived hepatitis $B$ vaccines. Br Med J 1986;292:159-161.

7. Carman WF, Zanetti AR, Karayiannis P, Waters J, Manzillo G, Tanzi E, Zuckerman AJ, et al. Vaccine-induced escape mutant of hepatitis B virus. Lancet 1990;336:325-329.

8. Szmuness W, Stevens CE, Harley EJ, Zang EA, Alter HJ, Taylor PE, DeVera $A$, et al. Hepatitis $B$ vaccine in medical staff of hemodialysis units: efficacy and subtype cross-protection. N Engl J Med 1982;307:14811486.

9. MCMahon G, Ehrlich P, Moustafa Z, McCarthy LA, Dottavio D, Tolpin $M D, N$ adler $\mathrm{PI}$, et al. Genetic alterations in the gene encoding the major HBsAg: DNA and immunological analysis of recurrent $\mathrm{HBSAg}$ derived from monoclonal antibody-treated liver transplant patients. HEPATOLOGY 1992;15:758-766.

10. MCNair ANB, Viaggi P, Smith HM, Tibbs CJ, Naoumov NV, Williams R. Hepatitis B envelope protein mutants. Lancet 1995;346:318-319.

11. Hawkins AE, Gilson RJC, Gilbert N, Wreghitt TJ, Gray JJ, Ahlers-de Boer I, Tedder RS, et al. Hepatitis B virus surface mutations associated with infection after liver transplantation. J Hepatol 1996;24:8-14.

12. Carman WF, Trautwein C, van Deursen FJ, Colman K, Dornan E, Mclntyre G, Waters J, et al. Hepatitis B virus envelope variation after transplantation with and without hepatitis B immune globulin prophylaxis. Hepatology 1996;24:489-493.

13. Waters JA, Kennedy M, Voet P, Hauser P, Petre J, Carman W, Thomas HC. Loss of the common " $a$ " determinant of hepatitis B surface antigen by a vaccine-induced escape mutant. I Clin Invest 1992;90:2543-47.

14. Villamil FG, Pan SH, Kuhns MC, Podesta LG, Sher L, Makowka L, Vierling JM. Efficacy and cost of long-term intramuscular hepatitis $B$ immunoglobulin ( $\mathrm{HBIG}$ ) in liver transplantation (LT) for hepatitis $B$ [Abstract]. HePATOLOGy 1994;20:129A.

15. Jameson BA, Wolf $H$. The antigenic index: a novel algorithm for predicting antigenic determinants. Comput Appl Biosci 1988;4:181-186.

16. Norder H, Hammas B, Lee SD, Bile K, Courouce AM, Mushahwar IK, Magnius LO. Genetic relatedness of hepatitis B viral strains of diverse geographical origin and natural variations in the primary structure of the surface antigen. J Gen Virol 1993;74:1341-1348.

17. Okamoto H, Imai M, Tsuda F, Tanaka T, Miyakawa Y, Mayumi M. Point mutation in the $S$ gene of hepatitis $B$ virus for a $d / y$ or w/r subtypic change in two blood donors carrying a surface antigen of compound subtype adyr or adwr. J Virol 1987;61:3030-3034.

18. M CC ory RW, Ishitani MB, Oliveira WM, Stevenson WC, M CCullough CS, Disckson RC, Caldwell SH, et al. Improved outcome of orthotopic liver transplantation for chronic hepatitis $B$ cirrhosis with aggressive passive immunization. Transplantation 1996;61:1358-1364.

19. Harrison TJ, Hopes EA, Oon CJ, Zanetti AR, Zuckerman AJ. Independent emergence of a vaccine-induced escape mutant of hepatitis $B$ virus. J Hepatol 1991;13(Suppl 4):S105-107.

20. Hino K, Okuda M, Hashimoto O, Ishiko H, Okazaki M, Fujii K, Hanada $\mathrm{H}$, et al. Glycine-to-arginine substitution at codon 145 of HBsAg in two infants born to hepatitis B antigen-positive carrier. Dig Dis Sci 1995;40: 566-570.

21. Fujii H, Moriyama K, Sakamoto N, Kondo T, Yasuda K, Hiraizumi $Y$, Yamazaki M, et al. Gly ${ }^{145}$ to Arg substitution in HBs antigen of immune escape mutant of hepatitis B virus. Biochem Biophys Res Commun 1992;184:1152-1157.

22. Bruce SA, Murray K. Mutations of some critical amino acid residues in the hepatitis B virus surface antigen. J Med Virol 1995;46:157-161.

23. Neurath AR, Pride MW, Strick N, Thanavala YM. Toleration of amino 
acid substitutions within hepatitis B virus envelope protein epitopes established by peptide replacement set analysis. I. Region S(139-147). Peptide Res 1990;3:116-122.

24. Borrego B, Novella IS, Giralt E, Andreau D, Domingo E. Distinct repertoire of antigenic variants of foot-and-mouth disease virus in the presence or absence of immune selection. J Virol 1993;67:6071-6079.

25. Jilg W, Delhoune C, Deinhardt F, Roumeliotou-Karayiannis AJ, Papaevangelou GJ, Mushahwar IK, Overby LR. Hepatitis B surface antigen (HBsAg) subtype-specific antibodies in persons vaccinated against hepatitis B. J Med Virol 1984;13:171-178.

26. Tai P, Banik D, Lin G, Pai S, Pai K, Lin MH, Yuoh G, et al. Novel and frequent mutations of hepatitis $B$ virus coincide with a major histocompatibility complex class-I restricted T-cell epitope of the surface antigen. J Virol 1997;71:4852-4856.
27. Hou J, Karayiannis P, Waters J, Luo K, Liang C, Thomas HC. A unique insertion in the $S$ gene of surface antigen-negative hepatitis $B$ virus Chinese carriers. HePATOLOGY 1995;21:273-278.

28. Lok ASF, Akarca US, Greene S. Mutations in the pre-core region of hepatitis $B$ virus serve to enhance the stability of the secondary structure of the pregenome encapsidation signal. Proc Natl Acad Sci U S A 1994;91:4077-4081.

29. Li JS, Tong SP, Wen YM, Vitvitski L, Zhang Q, Trepo C. Hepatitis B virus genotype A rarely circulates as an $\mathrm{HBe}$-minus mutant: possible contribution of a single nucleotide in the precore region. J Virol 1993;67:54025410.

30. Laskus T, Rakela J, Persing DH. The stem-loop structure of the cis-encapsidation signal is highly conserved in naturally occurring hepatitis B virus variants. Virology 1994;200:809-812. 